\title{
COGNITION, EPISTEMOLOGY, AND REASONING ABOUT EVIDENCE WITHIN THE LEGAL DOMAIN
}

\author{
Enrique CÁCERES
}

Resumen:

Tomando como punto de partida el modelo del fenómeno de la cognición de Humberto Maturana, y combinándolo con su propia propuesta teórica acerca de cómo entender al derecho (a la que denomina "Constructivismo Jurídico"), el autor analiza la compleja dinámica de la prueba judicial en términos de la manera en que la evidencia que las partes aducen en un juicio es cognitivamente procesada por los jueces.

$\mathrm{El}$ autor sostiene que, tal como sucede con los científicos, los jueces pertenecen a comunidades cognitivas. Sólo que, en su caso, se trata de comunidades cognitivas judiciales. La principal actividad cognitiva de estas comunidades consiste en una combinación de acoplamientos estructurales y clausura de operaciones cognitivas, las cuales son guiadas por las reglas autopoiéticas de la comunidad en cuestión.

En el modelo del autor, la evidencia es un constructo cognitivo, cuyo significado simbólico y peso están determinados por la manera en que la evidencia encaja en un contexto particular de relaciones entre varias clases de elementos, como el tipo de partes en conflicto, el tipo de pretensiones, el tipo de argumentos que ofrecen, etcétera.

Determinar si una proposición fáctica puede considerarse probada o no es el resultado de una clausura de operaciones cognitivas, la cual implica tomar en cuenta el carácter dialógico y derrotable de la argumentación jurídica.

* Translated by Edgar R. Aguilera, postgraduate student at the Instituto de Investigaciones Jurídicas, Universidad Nacional Autónoma de México.

** Coordinator of the Philosophy of Law Area within the Instituto de Investigaciones Jurídicas, Universidad Nacional Autónoma de México. 


\section{ENRIQUE CÁCERES}

Abstract:

Taking as a point of departure Maturana's model of cognition, and combining it with his own general approach to the law, which he calls "Legal Constructivism", the author analyzes the complex dynamics of judicial proof in terms of explaining how judges cognitively process the evidence put forward by the parties during a trial.

The author advances the view that judges, just as scientists do, belong to a certain cognitive community, that is, to a certain judicial cognitive community. The main cognitive activities of its members are a combination of cognitive structure-matching procedures and operational closures which are both regulated by the community's autopoietic rules.

Under his analysis, evidence is a cognitive construct. Its symbolic significance and weight is determined by how it fits within the context of a particular set of relations between elements such as the type of disputing parties, the type of claims and arguments made by them, and so forth.

Determining if a factual assertion can be considered proven or not under the author's model is the result of a cognitive operational closure that amounts to take into consideration the dialogical and defeasible character of legal argumentation. 
Summary: I. Cognition and Epistemology. II. Biology of Cognition as a Point of Departure. III. Autopoiesis and the Theory of Knowledge. IV. Autopoiesis and Cognitive Communities. V. Epistemology and Legal Constructivism. VI. Constructivism, Legal Evidence, and Artificial Intelligence. VII. Possible Implications of Assuming a Legal Constructivist Perspective in the Design of Legal Epistemology's Agenda. Open Questions.

\section{Cognition And Epistemology}

Along with Alvin Goldman I take epistemology's contemporary role to be a multi-disciplinary enterprise instead of being just another expression of "pure" or "aprioristic" philosophy.

In fact, the relationship between empirical research and epistemology is rarely considered in the literature. I think we owe this to some prejudices regarding the way epistemological investigations should be carried out. According to Goldman, the work of an epistemologist can be conceived as follows:

1) For some, epistemology must be autonomous in the sense of being prior, and therefore, a guide to orient scientific work. For this position, epistemology cannot be assisted by science in any important way.

2) For others, epistemology is focused on the analysis of some basic concepts such as "knowledge", "justification", "truth", "rationality", etcetera. Hence, it lies within the domain of linguistic philosophy.

3) Another position sees epistemology's job to be the study of methodology, and thus, for them epistemology lies within the boundaries of formal disciplines such as deductive or inductive logics, probability theory, etcetera. 
4) There are others who think of epistemology as being a prescriptive discourse which is focused on launching a critique to current epistemological practices.

As we can observe, within this spectrum of positions there seems to be no room for empirical research. Nonetheless, I think that none of the positions just described represents the only and correct way of doing epistemology. I also think that they are not necessarily incompatible with each other and with empirical research as well: Conceptual clarification is a pre-condition to epistemological evaluations and at the level of meta-logics too. Conceptual clarification is also a necessary condition within the semantics of any empirical theory from which a diagnosis of current states of affairs can be performed. These states of affairs can be modified via the application of the empirical theory itself. Thus, empirical research is compatible with a critical dimension too. And last, but not least, the relationship between empirical research and formal disciplines becomes evident if we consider that particular theories are but interpretations of some formal language.

In the same order of ideas, the justification of a naturalized epistemology can be said to have the same status of contemporary philosophy of mind.

\section{Biology of Cognition as A Point of Departure}

The biologist and epistemologist from Chile Humberto Maturana, ${ }^{1}$ has developed a theoretical framework of cognition. At the core of this framework lies the concept of "autopoiesis". For the author, it is possible to find system-like properties in almost any living organism. According to Torres Nafarrete, ${ }^{2}$ the model has the following elements:

1 See Maturana, Humberto and Varela, Francisco, The Tree of Knowledge, Shambhala, march, 1992, 269 pages. Also see, Maturana, Humberto, Autopoiesis and Cognition: The realization of the living, Springer, 1991, 180 pages.

2 See, Maturana, Humberto, La realidad, Objetiva o Construida? Fundamentos biológicos de la realidad, Anthropos Editorial, 1996. The book has an introduction of Javier Torres Navarrete. 
A) Autonomy. Every living organism isolates itself from its environment just like cells are separate from each other via the boundary membrane that each one has. This autonomy principle does not imply that the organism does not have any contact whatsoever with its environment. Consider how the same cell's membrane allows for an exchange of chemical compounds with other cells.

B) Emergence or supervenience. This property refers to the transition from an organism's state 1 to an organism's state 2. The link between the two (or n') states is not of causation. This is that it would be a wrong description to say that state 1 produced (caused) the state 2 . The subvenient and the supervenient states are not merely a superposition of states where the subvenient one keeps its identity. The transition to a supervenient state implies a structural modification of the subvenient one, just as the electrical charge of atoms is transformed when the order of the macromolecules emerges.

C) Operation's Closure. This property amounts for the phase within a process where a balance point has been reached. Reaching the balance point determines a transition to another state within the system (regulated by its own autopoietic rules). Of course, there is a tight connection between an operation's closure and the transition from a subvenient state to a supervenient one.

D) Self-constructing structures. This property amounts for the organism's ability to generate structures. The architecture of the structures generated at a certain point in time determines the architecture of future structures, just as what happens in the "Tetrix" game or in chess. Changes from one structure to another are carried out by means of adaptive procedures, which are self-induced. 
E) Autopoiesis. It is a property of certain systems, such as living organisms, or legal systems as well, that consists of counting with self-generation and preservation rules.

\section{Autopoiesis And The Theory of Knowledge}

Torres Nafarrete when referring to Maturana says that the dichotomy of rationalism/empirism implies two traps or faulty assumptions:

The first one has to do with rationalism (whose extreme version is solipsism). The faulty assumption is to consider that operations' closures take place in cognitive solitude. This perspective fails to give an account of the commensurability between the cognizing subject's internal configurations and the environment's behavior which is understood and structured reflecting the cognizing subject's internal configurations.

Related to empirism, the faulty assumption has been to consider that the nervous system produces isomorphic representations of reality when in fact, the way it works is determined by its own operational closures activities.

When we face these faulty assumptions, along with Maturana, we can say that knowledge is produced within the cognizing agent always. The cognizing agent never "touches" reality directly. Knowledge is the result of the diverse operational closures and structure-matching procedures that take place also within the cognizing subject. These structure-matching procedures are themselves the result of perceiving relevant disturbances (from the standpoint of the system's own rules) that produce cognitive dissonance. The way cognitive consonance is restored is precisely via the implementation of structure-matching procedures that give rise to new supervenient states or structures (which imply as well operational closures). These supervenient structures are themselves commensurable with the environment's behavior, as it is in the case 
of scientific theories. But this doesn't imply that the supervenient cognitive structures "match" the already given structure of a supposed external reality. Supervenient structures need not to be commensurable with the environment's behavior all the time. For instance, in the case of religious systems of beliefs or political ideology there is no need for empirical referents.

\section{Autopoiesis And Cognitive Communities}

Autopoietic theory has had applications in fields of knowledge such as the sociological theory proposed by Niklas Luhmann, ${ }^{3}$ or the legal domain such as Gunther Teubner's ${ }^{4}$ attempt to apply the notion of autopoiesis in the law. Those applications are not of my concern for now. Instead I will refer to the autopoietic phenomena as they manifest in the scientific communities.

Along with Maturana, I consider scientific practices and legal practices such as that of judges when solving disputed legal cases, as being both cognitive activities. Saying this implies that there is a cognitive community organized in order to carry out the activity in question. The members of the community have an arsenal of cognitive processing rules and contents at their disposal. These rules and contents are immersed in the dynamics of the implementation of structure-matching procedures and of operational closures. The difference between a cognizing agent that subscribes to a scientific paradigm and the legal operator is that while the first one is equipped with cognitive processing rules that allow him/her to produce supervenient cognitive structures that are commensurable with the natural world, the judge's supervenient structures are commensu-

3 See Luhmann, Niklas, Social Systems, Stanford University Press, United States of America, 1996.

4 See Teubner, Gunther, Autopoietic Law: A New Approach to Law and Society, Walter de Gruyter, 1987. 
rable only with a specific cultural context that is systematically generated.

If the cognitive events experienced by a cognizing agent are regulated by certain autopoietic cognitive rules, we can say that communication among members of the communities in question also presupposes certain structure-matching rules. This lies at the core of scientific and legal discussions where the accepted conclusions are but a cognitive state emerging out of an operational closure which is constrained by the parameters generated inside the paradigm or community in question.

Following Vygotsky's ideas, ${ }^{5}$ we can say that there are no individual minds. Instead, each mind is a collective product. In this same line, we can add along with Bateson ${ }^{6}$, that there is not only one kind of socially generated mind, but different "situational selves" that get activated depending on the social network that at a given time acts as a determining context and as a trigger of the situational self.

\section{EPISTEMology AND LEGAl CONSTRUCTIVISM}

Consider the following:

The sea is just sea, waves that endlessly come and go. Nonetheless lawyers distinguish national seas from international seas, and severe consequences follow from the trespassing of the boundaries of the national ones without an authorization of the Host State. But, where exactly is the line dividing both seas? It can not be any kind of artifact floating in the sea, because it would only be a signal of a pre-constituted division. The artifact does not itself constitute the boundary.

5 See Vygotsky, Lev, Mind in society: Development of higher psychological processes, 14th. ed., Harvard University Press, United States of America, 1978.

6 See Bateson, Gregory, Mind and Nature: Anecessary Unity (Advances in System Theory, Complexity, and the Human Sciences), Hampton Press, United States of America, August, 2002. 
If we go about answering this question assuming a traditional empirist position, we simply could not deliver the goods due to the lack of an empirical referent in terms of a "brute" reality to point at.

The distinction between national and international seas is but an external projection of a supervenient cognitive state (which emerged out of an operation's fulfillment) that took place in the mind of lawyers according to the information processing rules of their legal communities. That is to say that the distinction is the result of processing information in a certain way and there is strictly speaking, no outside structure of the world that corresponds to that notion.

Clearly, the source of the cognitive schemes supporting the belief that there are national and international seas is of a linguistic type (the international treaties establishing the boundaries). Despite that the text of the relevant treaty is open to be read by anybody, and despite its apparent objectivity, we know that what is important is not the sentence or statement by itself, but the legal proposition associated to it which constitutes its meaning. And we know that propositions are mental entities.

We also know that the relevant treaty can be no longer applied due to the exercise of derogatory powers conferred to legal operators. In the scenario where the relevant treaty no longer applies, it would still be possible to identify the statements or sentences in the text. It would also be possible to have a discussion about the different plausible meaning attributions to the sentence(s) according to different legal interpretation techniques. Nevertheless, the meaningful unit would no longer count as part of the legal system for the community. But, what exactly changed in this scenario? We can say that legal operators have first identified a disturbance in their environment (the declaration that the treaty is no longer applicable by a competent legal officer. Note that the presence of this disturbance could not have been identified by someone who didn't have preliminary legal notions such as the notion of a derogatory power, the 
concept of a legal system, etcetera). This disturbance has produced a cognitive dissonance which has given rise to a quest for a new state of balance. The final stage of that quest has been the implementation of a structure-matching procedure followed by an operational closure. A new supervenient state can be said to have raised, that of the belief that the treaty is no longer applicable. The belief that the treaty is applicable has been deleted. This change in the legal operators' systems of beliefs has important practical consequences as we all know.

Suppose now that the treaty remains applicable but with a modification of the boundaries of the national seas of the state in question. As in the later case, the new normative statement modifying the limits would have a cognitive constitutive effect in terms of giving rise to the corresponding belief which is source of new behavioral patterns.

We can also imagine another scenario where the modifications of the treaty involve the incorporation of a set of exceptions to the prohibition to trespass the relevant national seas, such as "urgent need". It may be the case that it remains unclear if a given particular event lies within the extension of the concept of "urgent need". The international courts would have to solve the matter. The international proceedings would characterize themselves as being a dialogical and defeasible process where both parties would put forward their arguments supported by the available evidence in order to obtain from the court the declaration that their assertions have been proven to the relevant standard.

In situations like the previously described we no longer find an isolated cognizing agent. Instead, we are dealing with cognitive processes that take place within a system conformed by a given cognitive community (the judge and the parties). As with scientific communities, the identification of a disturbance in the environment, the activation of prior cognitive schemes, and the following information processing that will ultimately lead to the implementation of structure-matching procedures and to the operational clo- 
sures from which a supervenient structure will arise (the verdict), are themselves regulated by the validation rules that are characteristic of the relevant legal community.

From a legal constructivist perspective the process where legal arguments and counter-arguments are put forward can be described as a dialogical process between two different cognitive structures offered by two cognizing agents who attempt to induce an operational closure within the judge, from which the corresponding supervenient state (the verdict) may emerge.

Nevertheless framing legal dispute resolution procedures in terms of dialogical and defeasible confrontation between arguments is an oversimplification. If one thing has become clear during the research that I've been conducting within the domain of Artificial Intelligence Applied to Law (AI and Law) is that the constructivist character of the law is present even before the development of the cognitive schemes that correspond to particular argument schemes can take place within the minds of the judge and of the parties.

Thus, perhaps now it seems more clearly that legal operators' deployment of legal behavior is carried out on the basis of the supervenience of what I call normative constructs inside their minds, which are the result of conexionist cognitive operations by means of which, diverse linguistic entities coming from different legal sources (statutory law, precedent, jurisprudence, etc.) are linked, get processed and transformed. These conexionist cognitive operations which are structural in nature have to be added with the semantic (for instance when the legal operator has to deal with an open textured-legal term) and hermeneutic (the application of different interpretation methods each of which produces a certain range of legal propositions) processing of legal inputs.

For its part, judges' cognizing activities take place at an epistemic niche (the court room). This means that they don't have direct access to brute facts. From an empirist position the facts of a particular disputed legal case re- 
ported via the relevant assertions made by the parties involved would not be susceptible to corroboration due precisely to this lack of witnessing the facts directly by the judge. In other words, a correspondence between assertions (propositions) and the world could not be established. So, if it is not with brute facts that the judge works with, the constructivist view states that the central element of her cognizing activities is the development of mental representations of what should have been the case in the world. The configuration of these mental representations of the facts of a case presuppose the prior development of the relevant normative construct(s), which just as happens in the "Tetrix" game, determines the configuration of the mental representations of facts. The emergence of these mental representations of the facts of a case is due to the processing of new legal inputs such as the evidentiary elements that the parties provide to support their claims. Again, the dynamics of the system is emphasized at this stage along with the need of more operational closures given that dialogical confrontations can take place between probandum propositions (which are contradictory with respect to each other), but also between evidentiary elements that provide different degrees of justification to the propositions that they are associated to.

It is worth mentioning that in contrast with the scientific domain, in the legal one there are but very few empirical referents that are perceptible through sensory experience. Nonetheless, their representational value is determined by prior cognitive schemes. Similarly to the case of anthropology where bones (empirical referents) are relevant for a theory of filogenesis not because of the bones themselves but because of the theory, a corps is relevant to criminal law investigations not because of the dead body itself, but because of the cognitive scheme which describes the crime of homicide, and because of the cognitive scheme that orients the legal operator on how to go about issues having to do with the gathering and the interpretation of evidence. Following this 
line of reasoning, the same empirical referent is susceptible to be interpreted through different cognitive schemes that the legal operator may retrieve, such as homicide, manslaughter, involuntary murder, etcetera. Furtherly, even in the case where the prosecutor witnesses a probable murder she would not be entitled to conclude just yet, that there has been a homicide without discarding alternative solutions to the case that may imply that the suspect acted on grounds of self-defense or on reasons of insanity.

As previously mentioned, in the legal domain there are relatively few cases in which we can point to an empirical referent perceptible through sensory experience. Along with homicide, physical injuries and property damages cases, there is a whole range of situations that emphasize that the construction of legal reality takes place inside the cognizing agent's mind. For instance, consider the case where the appellate courts have to determine whether the lower judge performed an adequate assessment of the evidence or not, or whether the lower judge correctly justified her decision or not. Consider also the case where the presence of internal mental states such as "the intention to commit fraud" has to be determined by the judge.

It is also worth mentioning that, at least in Roman-law countries like my own, evidentiary elements are mostly of a linguistic nature. Witnesses have to render their testimony in a written format. So do expert witnesses and people that confess to their crimes. This means that legal evidence makes sense depending on how it is processed by the cognizing agent based on the available cognitive schemes.

\section{Constructivism, Legal Evidence, And ARTificial INTELLIGENCE}

Most of the literature about legal evidence and proof assume what I here will call "an externalist" perspective. From this standpoint, legal evidence is "out there" to be gathered, and most importantly, to be assessed by legal operators. This externalist assumption underlies the research 
on graphic representation of legal evidence; the research on formal models that capture the dynamics of weight attribution to evidentiary elements; the research on coherentist and Inference to the Best Explanation models of evidence assessment; etcetera.

Nonetheless, approaching legal evidence and proof from a constructivist point of view sheds light on aspects that the externalist approach couldn't account for. I have arrived to this conclusion due to my experience in the field of judicial knowledge elicitation within an Artificial Intelligence and Law project that I am currently conducting at the Legal Research Institute of Mexico's National University (UNAM). The project is sponsored by the Science and Technology National Research Council (CONACYT), with the valuable collaboration of the Supreme Court of the State of Tabasco.

Some results of the research:

\section{Legal evidentiary elements as cognitive inputs}

As stated above, the externalist approach assumes that legal evidence already is out there. For the constructivist approach, legal evidence would be a cognitive construct in the minds of legal operators.

Legal evidence gets its internal symbolic value within the context of prior schemes and systems of beliefs that are retrieved or adapted in the memory's search space of the cognizing agent (the judge).

\section{Legal evidence's internal symbolic value} is determined in a co-dependent fashion

An evidentiary element acquires its meaning or gets its internal symbolic value according to the cognitive scheme in which it is inserted. For its part, this scheme performs the function of a cognitive context. Among the elements that constitute the cognitive contexts in which different evidentiary elements are inserted, we can name the following: The different probandum propositions to which the parties 
are committed. Each normative feature such as the normative subject, the deontic status of the behavior, the behavior itself, etcetera. may have probandum propositions associated to it; the number and contents of evidentiary elements associated to each probandum proposition; the relation between evidence and counter-evidence; etcetera.

\section{Legal evidence is relatively objective}

Information given by witnesses and by people who confess to their crimes is already a manifestation of a particular way of organizing the perceived disturbances in the environment into a mental representation with specific contents. So, witnesses' declarations which are ultimately propositions do not "paint" the way the world out there is. Experimental research conducted in the field of witnesses' memory has shown that the "same" facts may be perceived differently by two or more witnesses. It has also shown how the testimony of the same witness changes over time with- out the witness's conscious control.

In the case of expert testimony, the scenario is very similar. Experts do not deal with already pre-structured problems or situations. They must make a choice on how to approach the problem; they must choose the appropriate strategy; etcetera. These choices are themselves the result of cognitive operations that allow them to fix their object of analysis. The fact that Mexican procedural law establishes the possibility of having contradictory expert testimonies is a clear sign of this phenomenon.

Regarding documents, whether they are private or issued by public officers, they do not have a unique meaning. In a certain sense, they are recreations of the reader.

\section{Procedural law and cognitive processing}

As stated elsewhere, some of the prescriptive propositions of statutory law are directives that regulate judicial cogni- 
tive processes. Among them we can name the very characteristic case of Roman-Law countries of rules that establish a pre-determined weight that must be attributed to a certain evidentiary element; the rule establishing the standard of proof; etc. These rules are the source of what is called the "judicial procedural knowledge". It may happen that the contents of those directives vary across jurisdictions (even in the same country). This implies that the evidence supporting the claims of two or more very similar cases may be assessed very differently depending on the jurisdiction in question. Differences may become more evident if a similar case is tried in courts belonging to different countries or to different legal traditions. It seems in the light of the prior phenomenon, that talk about truth in law is meaningless.

\section{Evidentiary elements as cognitive constructs}

Based on the previous discussion, it may be clearer why I hold that judges solve disputed legal cases based on the mental representations of the facts of the case that they are able to devise according to the relevant cognitive processing rules in their community. The thesis goes farther. Evidentiary elements are themselves cognitive constructs that contribute (in a gestalt-like fashion) to the process of the configuration of the cognitive structures emerging out of the sub-decisions and the final decision (the verdict) of a legal process.

VII. Possible Implications of Assuming a Legal Constructivist Perspective in the Design of Legal EPISTEMOLOGY's AGENDA. OpEn QUestions

\section{The problem of "truth"}

What would be the implications of assuming a constructivist perspective regarding what Larry Laudan has called 
"legal epistemology's hard core"7 (regarding legal epistemology's aim to reduce epistemic errors through out trials)?

Of course, giving an answer will depend on the theory of truth one is willing to adopt. For instance, for the empirist (correspondentist) determining legal truth is a matter of establishing a correspondence between what we have called the cognitive operational closures and the already given, external and objective structure.

For the constructivist view, the determination of legal truth is but the cognitive result emerging out of the cognitive operational closures carried out by legal operators. A constructivist stance makes the following two remarks about the activity a judge engages in when solving disputed legal cases:

First of all, the remark about the constitutive function performed by the normative constructs. Once a normative construct has emerged in the legal operator's mind, it establishes for her certain conditions that must be met by particular acts in order for them to be considered as legally relevant. For instance, only because Mexican Statutory Law establishes the obligation of every Mexican Citizen to pay what we call "Tax over Incomes" (or whatever tax) that it becomes possible that someone commits the crime of "tax evasion" (related to this kind of tax). In this sense the role of legal discourse is similar to what Searle called "constitutive rules", and the particular act falling within "tax evasion"'s extension would be similar to Searle's "institutional facts" (in this case, legal institutional facts). ${ }^{8}$

The other remark has to do with the judge's declaration that someone actually committed tax evasion. At this stage, the judge is constrained by the cognitive operational closures she is able to carry out according to the cognitive

7 See Laudan, Larry, Truth, Error, and Criminal Law: An Essay in Legal Epistemology, Cambridge University Press, 2006, 254 pages.

8 See Searle, John, The Construction of Social Reality, Free Press, 1997, 256 pages. 
schemes she may retrieve and to the characteristics of the particular case.

Of course, it may be the case that there is no correspondence between what "really" happened in terms of the particular institutional fact and the determination on behalf of the judge that someone actually committed the crime. While this may be so, and guilty people may get away with it and innocent people may be falsely convicted, we don't have to loose sight on the fact that in any case the possibility to have an institutional discussion (a criminal procedure) about whether a particular act is an instance of tax evasion or not is created by the legal discourse's constitutive effect on legal operators' minds. If the article of the criminal code describing "tax evasion" were no longer applicable due to the exercise of derogatory powers conferred to some legal officer, the possibility to identify particular acts as instances of "tax evasion" would have faded away along with the article's validity.

\section{About epistemic errors}

Assuming a constructivist perspective as a framework to explain the judge's cognizing activities when solving disputed legal cases would have another implication which is to translate the concern of reducing errors such as false convictions or false acquittals in the case of criminal law, as a problem of warranting the best quality possible when executing the cognitive rules regulating the declaration on behalf of the judge that the facts described by the parties have been the case.

The declaration on behalf of the judge that something was the case evidently (at least in the criminal law) must pursue, as a regulatory ideal, the objective of being the nearest possible to what actually took place in the world (to what we have called the institutional legal fact). Stating the latter as a regulatory ideal is tightly related to the cognitive notion of the brain as a servo-mechanism; in other words, 
as a defined purpose device. The process that consists of devising a mental representation whose content is conceived as a desired target by the cognizing agent and how cognitive resources get organized in order to achieve the goal in question is known as "a determinant tendency".

Determinant tendencies perform a very important role in the way that the cognitive system will retrieve and generate schemes that are cogent with the particular tendency at place. General planning in the field of management is a suitable example of this process, where the determinant tendencies would be the particular goals stated in the plan.

Based on a principle of cognitive resource-saving, our memory retrieves schemes that were successfully applied to prior analogue situations. These schemes are adapted into a new structure hoping to have the same effect in terms of success of the analogue schemes. For instance, if we ask a software engineer to design a data-base for our library what is more probable to happen is that the engineer will seek in his mental search space for analogue schemes that were successfully applied to challenges such as the one represented by our request. Most certainly he will have to make some adaptations in order to fit the new specified requirements. Based on that, he will specify the characteristics of the base; he will plan the programming strategy; and eventually, he will finish the new data-base.

Within the judicial arena, when expert judges deal with solving disputed legal cases they retrieve in their mental search spaces prior analogue schemes that had positive results in the past. Then, they go about the process of adapting those schemes into a new emerging structure via the implementation of structure-matching procedures and of cognitive operational closures.

It must not follow from what has been said, that determinant tendencies depend on the activation of prior successful schemes. There is always a novel case that calls for a fresh start in terms of devising a problem solving method from scratch. The possibility that this new scheme figures 
within the feedback process between prior schemes and present situations will depend on how well it performs.

\section{Truth and errors in Hart's penumbra zone}

Contrary to our tax evasion example, there are cases where prior to the judicial determination of the facts nobody was certain that the institutional fact occurred or not. These situations are very common in our Mexican administrative law which is plagued of vague and ambiguous terms and which nobody knows what meaning should be attributed to them prior to the first case of judicial application of the statute. In these cases the first judicial determination of the facts (which are decided to be instances of the relevant vague concept) acts as an a posteriori criterion that establishes the features that the institutional fact should have exhibited. It also states a precedent for future cases.

\section{Legal procedure and cognitive processes}

From a legal constructivist point of view, procedure rules are taken to be directives that regulate the cognitive activity of legal operators, particularly of judges. Perhaps this becomes more clearly if we say that these directives stand along propositions of the sort of "please, imagine that...", "think of...", "remember that...".

In the Mexican legal procedure rules, we can find examples of these directives in the section regarding what evidentiary elements may be offered by the parties in order to support their assertions; the section establishing the conditions that each evidentiary element must meet in order to be considered as validly offered; the section establishing, and this is very important and characteristic of Roman law tradition countries, pre-determined weights that must be attributed to particular evidentiary elements (for instance, the rule establishing that public documents leave no reasonable doubt of the facts stated in their text), etcetera. 
This means that procedural law performs a very important role in terms of supplying most of the cognitive rules regarding the configuration of schemes, supervenience, cognitive operational closures, etc. that are characteristic of the judicial community when determining the facts of disputed legal cases.

In addition, we can say that what we call "the substantive law" is the main source of declarative legal knowledge (which can be reformulated as legal ontologies, legal semantic webs, etcetera), while the procedural law is the main source of procedural knowledge.

5. Something about the Standard of Proof. Is reasonable doubt really as subjective as some claim it to be?

One of the most frequent critiques to terms that express legal standards of proof, such as "proof beyond all reasonable doubt" is that they are ill defined, vague, or even semantically indeterminate. This state of things makes the judicial determination of the facts of a disputed legal case a plainly subjective matter.

From a legal constructivist perspective, things look very differently. As we have seen the judges' cognitive properties make them "structurally constrained" (this is not to say that they are fatally determined). The constrains include their professional background and training; the way that initial cognitive structures or schemes get strengthen through the development of heuristic knowledge as a result of having solved a variety of prior cases more or less successfully; the control exercised by the appellate courts; and the ongoing feedback coming from the rest of the legal community. All these constraints constitute the current intersubjective criteria of information processing at operation in the judicial community at a given time.

Based on this, we can understand that the term "proof beyond all reasonable doubt" denotes an emerging cognitive 
state that supervenes on multiple cognitive tasks and structure-matching procedures carried out in each disputed legal case. Among the cognitive sub-tasks that judges carry out we can name for instance, classificatory tasks, decision tasks, etcetera.

It does not follow from this line of reasoning that we claim that every judge will process similar information in the same way. With respect to this point, it is important to note that, within certain parameters, judges perform their duties according to the principle of cognitive individualization. This means that a disputed legal case can have a variety of plausible legal solutions. Nonetheless, diversity does not imply that there can not be a selection of the best solution proposals. 